\title{
Los ámbitos de la competencia comunicativa de los académicos de la Universidad Autónoma de Chihuahua
}

\section{Lourdes Carrillo Vargas \\ Jorge Cortés Montalvo}

Profesores investigadores Universidad Autónoma de Chihuahua

\section{Resumen}

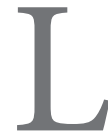

a transformación educativa en este mundo globalizado donde el modelo por competencias instaura nuevos roles en los actores educativos, establece en el académico universitario la necesidad de vincular los diversos ámbitos de competencia comunicativa como son: la adquisición de lenguajes, la tecno-competencia, la media-competencia y la info-competencia, en el proceso de generación de productos de calidad y su colocación en los diversos circuitos mediáticos, estableciendo nuevos estados del conocimiento con la finalidad de insertarse en la innovación y actualización educativa.

Palabras clave: competencias, info-competencia, media-competencia, tecno-competencia

\section{Introducción}

Las instituciones de Educación Superior a la luz del enfoque de las competencias, se han dado a la tarea de planear y aplicar diversas estrategias que favorezcan la innovación, la divulgación de los estándares básicos encaminados a promover la formación de nuevos paradigmas, propiciadores de una educación superior que cumpla con los lineamientos internacionales requeridos por la sociedad contemporánea.

El siglo XXI es génesis de nuevos alfabetismos, tales como la utilización de las tecnologías de la información y de la comunicación (TIC) y el surgimiento de diversos circuitos mediáticos que marcan la pauta de una actualización para el manejo de nuevos dispositivos, identificación de diversas fuentes y modalidades de recuperación de información, para apli- 
car criterios de selección, análisis y generación de nuevo conocimiento; esto conlleva a una modalidad educativa que responda a las necesidades de la sociedad contemporánea y su dinámica transformación. La Unesco (1998) establece que se debe preparar a la juventud para vivir en un mundo mediático. El planteamiento educativo tiene como objetivo el formar ciudadanos eficaces, reflexivos y críticos capaces de analizar y construir nuevos conocimientos que sean viables para ser transmitidos en diversos circuitos mediáticos existentes en la actualidad. Por tal motivo el académico universitario se ve envuelto en procesos de transformación que requieren de disposición al cambio y generación de conocimientos que le provean de herramientas significativas en el entorno social y educativo.

Berio (2006) refiere que actualmente la información del mundo que nos rodea nos llega no solamente en palabras escritas sobre papel sino, cada vez con mayor frecuencia, mediante imágenes y sonidos provenientes de nuestra cultura multimediática.

De ahí la importancia de la concientización y acción del académico universitario, la innovación de su práctica, adquiriendo nociones básicas de tecnología que le permitan involucrarse de forma asertiva en diferentes escenarios, propiciando la creación y difusión de nuevos conocimientos y su colocación en diversos circuitos mediáticos.

A partir de la identificación de esta problemática surge este proyecto de investigación, realizado en la Universidad Autónoma de Chihuahua, en donde 236 académicos con reconocimiento de perfil PromeP y/o SNI, consi- derados como investigadores y generadores de conocimiento, dan testimonio de las competencias que ponen en juego en su proceso creativo, particularmente en aquellos aspectos vinculados con los ámbitos de la competencia comunicativa como base fundamental de este proceso.

Los lineamientos para pertenecer al perfil Promer y SNI son claros y objetivos; se trata de académicos que realizan diversas funciones como docencia, gestión, tutorías e investigación y deben cumplir con los requerimientos marcados por la Academia de Ciencias y el ConACrt. Se establecen para esta investigación cuatro ejes específicos: el primero es identificar los productos de conocimiento realizando una estimación, cuantificación y clasificación. El segundo se refiere a la identificación de los diversos circuitos mediáticos de difusión con el fin de verificarlos, cuantificarlos y valorarlos; es importante conocer en dónde y bajo qué condiciones de selección de medios se colocan los productos. En el tercer eje se analizan los mecanismos de renovación de los cuadros docentes con la finalidad de identificar y realizar un análisis comparativo de planes y políticas universitarias, contrastando el plan institucional, plan por DES y el plan por unidad académica, para verificar las competencias requeridas o 'repertorio de entrada' de los cuadros académicos en conformación.

Por último, es importante identificar los dominios específicos que suelen poner en práctica los Docentes Universitarios en funciones, en distintas áreas de conocimiento, disciplinas y ámbitos artísticos y creativos, para la generación de productos de calidad. 


\section{Metodología}

El plan de acción que integra esta investigación, se llevó a cabo en diversas etapas: la consulta a directores, ex directores y secretarios académicos de cada facultad o unidad académica, por medio de entrevistas semiestructuradas, para establecer las estrategias y mecanismos en el proceso de renovación y reestructuración de cuadros académicos, e identificar puntos de acuerdo respecto a reglas, normas y políticas institucionales con ese propósito. Búsqueda de datos e información en fuentes primarias, tanto en la red como en las diferentes DES de la universidad, y otras universidades para el análisis comparativo, marcos teóricos referenciales y estado del arte. Con apoyo del Centro Universitario de Desarrollo Docente (CUDD), se realizaron talleres para investigadores, con formato de grupos focales, cuyo objetivo fue recoger de ellos información de primera mano sobre la generación de productos de calidad; a fin de conocer y analizar las estrategias que siguen, paso a paso, hasta la obtención de productos e identificar los criterios de selección y colocación de su producción en diversos circuitos mediáticos, con el afán de tener elementos que nos permitan establecer parámetros y categorías en la identificación de dominios y proponer acciones para su promoción institucional. Se llevó a cabo la aplicación de encuestas en formato escrito y digital, realizadas a todos los académicos de la $\mathrm{UACH}_{\mathrm{AC}}$ pertenecientes al SNI o con reconocimiento del perfil PromeP recabando información personal sobre su producción académica, sus procesos de generación y los circuitos mediáticos que utilizan para su difusión.

El modelo educativo basado en competencias tantas veces revisado, analizado y explica- do desde diferentes perspectivas por múltiples autores y organizaciones (McClelland 2008, Roegiers 2007, Perrenoud 2001, Zabalza 2003, Cano 2007, García et al 2008, Ocde 2003, entre otros) y no exento de críticas (Sacristán 2008), ha logrado imponerse como paradigma en la redefinición de los objetivos de la educación superior y opera, desde el año 2003, como canon académico en la UACH, según la propuesta de Marín (2006) .

Es relevante destacar que en la apreciación de estos autores siempre está presente la competencia comunicativa clasificada como genérica, básica, transversal, sin embargo los cuatro ámbitos de la competencia comunicativa se establecen en esta investigación como requerimientos específicos necesarios para la generación de nuevos productos:

a) La adquisición de lenguajes en donde el académico incorpora diversos repertorios lingüísticos, utiliza lenguajes científicos establecidos en las diversas áreas del conocimiento.

b) La tecno-competencia, destaca la necesidad de incrementar habilidades para integrar las TIC en sus actividades de docencia, gestión, tutorías e investigación, requiere fortalecer habilidades y destrezas para la operación de dispositivos electrónicos, equipos de cómputo, programas y sistemas digitales, además de la navegación por la red.

c) La info-competencia supone, de inicio, que el académico sepa plantear preguntas, estructurar problemas y definir objetivos, es preciso saber seleccionar información, analizarla, reflexionar sobre ella y ubicarla como pertinente y suficiente para dar respuesta a las preguntas formuladas, alcanzar los objetivos previstos 
o resolver efectivamente el problema planteado, es entonces cuando podemos decir que se está construyendo nuevo conocimiento, la difusión de este nuevo conocimiento, constituye otra variante de la competencia comunicativa.

d) La media-competencia, que significa un conjunto de saberes, capacidades, habilidades y actitudes desarrollados en torno a los medios de comunicación y la capacidad de reconocer y utilizar los mecanismos mediáticos para colocar en sus circuitos mensajes propios. Es primordial identificar que los circuitos digitales dan paso a una evolución gigantesca respecto a los productos en formato impreso (Cortés y Carrillo, 2010).

\section{Resultados}

La identificación y clasificación de la producción académica generada por los investigadores de la UACH, culmina en la elaboración de un catálogo de productos, puestos a disposición de la comunidad universitaria por medio de una base de datos, la cual da la pauta para establecer búsquedas específicas por autor, año, producto, DES. Con esto se brinda la oportunidad de acceso al nuevo conocimiento generado por los académicos. Esta base de datos está en proceso de evaluación para su colocación en la página oficial de la UACH. De forma sintetizada se organizó la producción en tres vertientes del trabajo académico: dentro del aula, como gestor y como investigador (ver cuadro 1).

\section{Cuadro 1}

\begin{tabular}{|c|c|c|}
\hline \multicolumn{3}{|c|}{ Producción del Académico de la UACH } \\
\hline Dentro del aula & Como gestor & Como investigador \\
\hline $\begin{array}{l}\text { Presentaciones power point } \\
\text { Antologías } \\
\text { Monografías } \\
\text { Cuadros de doble entrada } \\
\text { Material didáctico } \\
\text { Videograbaciones } \\
\text { Objetos de aprendizaje } \\
\text { Programas de asignaturas }\end{array}$ & $\begin{array}{l}\text { Reportes de estudiantes } \\
\text { Supervisión de servicio social y } \\
\text { prácticas profesionales } \\
\text { Diseño curricular } \\
\text { Planes institucionales }\end{array}$ & $\begin{array}{l}\text { Monografías; Proyectos de mejora } \\
\text { profesional; Catalogo e índices; Textos de } \\
\text { divulgación; Artículos científicos; Libros; } \\
\text { Capítulos de libros; } \\
\text { Obra artística: plástica, musical, danza, } \\
\text { teatro; Obra de ingeniería; Patentes; } \\
\text { Traducciones técnicas; Desarrollo de } \\
\text { software; Manuales; Banco y bases de } \\
\text { datos; Memorias de congreso; Ponencias } \\
\text { en congreso; Conferencia magistral; } \\
\text { Ensayos; Programas tv y radio; Guiones } \\
\text { técnicos; Compilación de libros; Reseñas; } \\
\text { Dictamen de productos científicos; } \\
\text { Dictamen de proyectos científicos. }\end{array}$ \\
\hline
\end{tabular}

Una vez identificados los productos generados por los académicos, se continuó con la tarea de especificar los parámetros de calidad, la categorización fue establecida en grupos focales de expertos que determinaron explícita- mente la generación y la ubicación en un tópico específico para un análisis concreto y claro. De igual forma se determinó su definición y los criterios específicos para denominarlo 'producto de calidad' como se muestra en el cuadro 2: 


\section{Cuadro 2}

\section{CRITERIOS DE CALIDAD}

- Ser claro, entendible, objetivo, concreto y específico

Estar avalados por la academia del área y/o academia institucional

Material específico entendible para cualquier lector

Pasar por un proceso de validación

El impacto del programa sobre la sociedad

Incluir: contextualización, justificación, objetivos, metodología, sistema de evaluación, cronograma

Sustentado en la identificación de una oportunidad de mejora en el campo profesional. Factible de aplicación

De acuerdo a criterios internacionales

Determinado por el medio específico del área

Sometidos a arbitraje con resultados positivos

Registrado con un ISBN, registrado en INDEAUTOR

Criterio de mercado que determina su aceptación

- Se consideran modelos de utilidad los objetos, utensilios, aparatos o herramientas que, como resultado de una modificación en su disposición, configuración, estructura o forma, presenten una función diferente respecto de las partes que lo integran o ventajas en cuanto a su utilidad. Y son novedad

- Requieren un alto nivel de destreza y conocimiento, por parte de la persona, de la terminología tratada

- Funcionamiento efectivo, eficaz y con facilidad de utilizarse

- Utilidad, eficacia y facilidad de manejo

- Características propias de áreas de conocimiento y editoriales

Pasar por un proceso de validación

Cubrir los lineamientos de calidad establecidos por el comité evaluador

Estos criterios están presentes de forma específica en la categorización de productos y sus propios requerimientos de calidad: conocer los procesos cognitivos a partir de investigaciones, colaboraciones, encuentros y redes académicas, culmina en la generación de productos; establecer procesos utilizados, muestra diferentes dominios de la competencia comunicativa; la info-competencia como dominio primordial para analizar los conocimientos ya generados en un área específica, brindando al académico la oportunidad de contribuir o modificar con sus aportaciones a determinadas esferas del conocimiento. La media-competencia involucra la difusión existente de los productos generados, muestra la trascendencia a diversos entornos del planeta en donde la distancia y la diversidad de lenguajes no son obstáculo para la difusión que propicia el intercambio académico, enriqueciendo el acervo educativo que favorece reformas y transformaciones en la Universidad. La adquisición de lenguajes y la tecno-competencia se visualizan en la presencia de los académicos en diversos entornos. 
Al recabar la información de los expertos pudimos lograr una categorización de ámbitos de

\section{Cuadro 3}

dominio vinculados con la competencia comunicativa en la generación de productos mostrados en el cuadro 3:

\begin{tabular}{|c|c|}
\hline & ÁM \\
\hline $\begin{array}{l}\text { Adquisición } \\
\text { de Lenguajes }\end{array}$ & $\begin{array}{l}\text { Capacidad de comunicación verbal en forma efectiva } \\
\text { Capacidad de comunicación escrita en forma efectiva } \\
\text { Habilidades de lectura e interpretación de textos científicos } \\
\text { Habilidad en el manejo de un segundo idioma; leer, escribir, escuchar y hablar } \\
\text { Habilidad en redacción científica que demuestre el buen uso y manejo de la información } \\
\text { Comunicación efectiva oral y escrita en función del contexto } \\
\text { Utiliza el diseño experimental apropiado en el planteamiento de un proyecto de investigación adecuándo- } \\
\text { se al lenguaje correspondiente } \\
\text { Habilidad en el manejo de lenguajes científicos específicos de cada área del conocimiento } \\
\text { Habilidad de síntesis en el lenguaje verbal y escrito }\end{array}$ \\
\hline $\begin{array}{l}\text { Info } \\
\text { Competencia }\end{array}$ & $\begin{array}{l}\text { Elaboración de propuestas de investigación, a partir de la identificación y análisis de problemas científicos, } \\
\text { apoyado en el uso eficiente de las fuentes documentales } \\
\text { Análisis y reflexión de los diferentes componentes de un problema y sus interrelaciones } \\
\text { Elaboración, interpretación, adecuación y aplicación de reportes de investigación con base en resultados } \\
\text { obtenidos } \\
\text { Identificación de necesidades problemáticas en el estado de conocimiento } \\
\text { Localizar, analizar y calificar información científica aplicando los principios para su organización } \\
\text { Contextualización de los productos en la cultura } \\
\text { Planear, analizar y abstraer información en diversos escenarios y situaciones en eventos a la luz del conoci- } \\
\text { miento } \\
\text { Habilidad en manejo de información para determinar las ideas donde el conocimiento es muy difuso o inci- } \\
\text { piente } \\
\text { Análisis para identificar el origen de situaciones problemáticas de fenómenos potencialmente estudiables } \\
\text { Adapta críticamente sus propios conceptos y comportamientos a normas, ambientes y situaciones cambian- } \\
\text { tes } \\
\text { Crea soluciones innovadoras y utiliza formas no convencionales en la solución de problemas, tiene disposi- } \\
\text { ción al cambio y a la ruptura de paradigmas establecidos }\end{array}$ \\
\hline $\begin{array}{l}\text { Media } \\
\text { Competencia }\end{array}$ & $\begin{array}{l}\text { Optimiza y enlaza recursos disponibles } \\
\text { Propicia la gestión de recursos } \\
\text { Conoce, adapta y manipula correctamente las tecnologías } \\
\text { Demuestra un buen dominio en el manejo de recursos documentales y electrónicos que apoyan la bús- } \\
\text { queda de información científica } \\
\text { Maneja y aplica paquetes computacionales para desarrollar documentos, presentaciones y bases de informa- } \\
\text { ción } \\
\text { Uso y manejo de programas computacionales para la presentación de sus trabajos escritos, así como de } \\
\text { apoyo audiovisual en la exposición de temas } \\
\text { Preparación y presentación oral de sus trabajos apoyándose en materiales audiovisuales incluyendo con- } \\
\text { clusiones estadísticas cuando así lo requiera } \\
\text { Maneja herramientas tecnológicas y metodológicas de investigación } \\
\text { Aplica la tecnología disponible a la solución de problemáticas }\end{array}$ \\
\hline $\begin{array}{l}\text { Tecno } \\
\text { Competencia }\end{array}$ & $\begin{array}{l}\text { Determina los requerimientos de los diversos circuitos mediáticos para su utilización } \\
\text { Localiza fuentes de información de calidad en su área de conocimiento. } \\
\text { Realiza análisis de impacto de las aportaciones al estado del conocimiento } \\
\text { Conocimiento de circuitos mediáticos } \\
\text { Optimiza y enlaza recursos disponibles } \\
\text { Identificación de medios de publicación } \\
\text { Comunica efectivamente los resultados de sus investigaciones, con participación en eventos académicos y } \\
\text { científicos }\end{array}$ \\
\hline
\end{tabular}


Los presentes dominios se especifican en el reporte de investigación categorizada por áreas de conocimiento, en donde se realizan diversas adecuaciones determinadas por el académico y sus productos generados.

\section{Conclusiones}

Surge entonces la alternativa de establecer mecanismos de actualización que fomenten el aprendizaje y dominio de los ámbitos establecidos por la competencia comunicativa con la elaboración de talleres, diplomados, especializaciones en el área disciplinar, del uso de tecnologías, en investigación y en la generación de productos académicos de diverso orden. Siempre avalados por expertos seleccionados por la universidad.

Referimos que el camino por andar es largo, que se requiere la disposición para la transformación y cambio de paradigmas para insertarse en este mundo globalizado del, que los actores educativos son pilares fundamentales para el desarrollo económico, social y cultural del país y es fundamental fomentar en el académico universitario la adquisición integral de competencias que fortalezcan y proyecten una estela de luz que impacte en los nuevos estados del conocimiento, recordar que lo que hoy es novedad mañana será historia.

\section{Referencias}

Berio, D. (2006). Comunicación y comportamiento. Recuperado el 20 de octubre de 2008, de EDUTEKA. http://themecraft.net/ www/eduteka.org

Cano, E. (2007). Cómo mejorar las competencias de los docentes: guía para la autoevaluación y el desarrollo de las competenicas del profesorado. Barcelona: GRAO.

Cortes Montalvo, J. Carrillo Vargas L. (2010): Elementos integradores de la competencia comunicativa en académicos universitarios. II Congreso Internacional Latina de Comunicación Social. Diciembre. Universidad de la Laguna. Canarias, España

García, C. B., Rueda, M., Luna, E., y Loredo, J. (2008). Modelo de evaluación de competencias docentes para la evaluación media y superior. Obtenido de Revista Iberoamericana de Evaluación Educativa: http://www.rinace.net/riee/numeros/vol1-num3_e/art8.pdf

Marín Uribe, R. (2006). El modelo Educativo de la UACH: elementos para su construcción. Chihuahua: Dirección de extensión y Difusión Cultural. UACH

McClelland, D. (2008). Testing for competnece rather than intelligen$c e$. En J.Vivancos, Tratamiento de la información y competencia digital (pág. 19). Madrid: Alianza Editorial.

OCDE. (2003). Análisis de Politicas educativas edicion 2003. http:// www.oecd.org/dataoecd/47/27/21062763.pdf

Perrenoud, P. (2001). La formación de los Docentes en el siglo XXI. Revista tecnologica Educativa, 503-523.

PROMEP. (2009). Preguntas más frecuentes sobre Cuerpos Académicos. Recuperado el 16 de 04 de 2009, de http://promep.sep. gob.mx: preguntasca.html\#CA

Roegiers, X. (2007). Pedagogía de la integración. Competencias e integración de los conocimientos en la enseñanza. San José de Costa Rica: AECI.

Sacristan, G. (2008). Educar por competencias, ¿qué hay de nuevo? Madrid: MORATA.

Unesco (1998). Educación Superior siglo XXI. Recuperado el 23 de enero de 2009, de www.unesco.org/education/educprog/ wche/declaration_spa.htm

Zabalza, M.Á. (2003). Competenicas docentes del profesorado universitario: calidad y desarrollo profesional. Madrid: NARCEA. 
